\title{
Quem violenta mulheres?: a construção social da masculinidade e sua influência na violência de gênero
}

\author{
Raissa Rayanne Gentil de Medeiros $^{1}$
}

\section{Resumo}

Este estudo objetivou analisar como a socialização dos homens contribui para a perpetuação da violência de gênero. Para isso, buscou analisar o conceito de gênero, identificar as diferenças na construção do feminino e masculino e investigar meios de combate à violência contra a mulher. A pesquisa foi realizada através de um levantamento bibliográfico acerca dos conceitos de gênero, masculinidade e violência contra a mulher, tendo como referenciais teóricos especialmente Joan Scott e Saffioti. O principal resultado da pesquisa consistiu na compreensão de que a construção social da masculinidade dentro de um sistema marcado pelo patriarcado acaba por formar homens que violentam mulheres, seja de forma física, sexual ou psicológica. Nos estudos de Erica Canuto (2018) foi encontrada a aplicação dos grupos reflexivos de homens como forma de solucionar o problema, vez que esses possibilitam a transformação dos padrões socioculturais.

Palavras-chave: masculinidades; gênero; violência doméstica.

\footnotetext{
${ }_{1}^{1}$ Mestranda no Programa de Pós-Graduação em Direito da Universidade Federal do Rio Grande do Sul (UFRGS). Bacharela em Direito pela Universidade Federal do Rio Grande do Norte (UFRN). Bolsista pela Coordenação de Aperfeiçoamento de Pessoal de Nível Superior (CAPES). E-mail: raissa.medeiros@hotmail.com
}

GT 21 - Gênero e Violência 


\title{
Who violates women?: the social construction of masculinity and its influence on gender violence
}

\begin{abstract}
This study aimed to analyze how men's socialization contributes to the perpetuation of gender violence. To this end, it sought to analyze the concept of gender, identify differences in the construction of women and men and investigate ways of combating violence against women. The research was carried out through a bibliographic survey about the concepts of gender, masculinity and violence against women, with theoretical references especially Joan Scott and Saffioti. The main result of the research was the understanding that the social construction of masculinity within a system marked by patriarchy ends up forming men who violate women, whether in a physical, sexual or psychological way. In the studies of Erica Canuto (2018) it was found the application of reflective groups of men as a way to solve the problem, since these enable the transformation of socio-cultural patterns.
\end{abstract}

Keywords: masculinities; gender. domestic violence.

\section{Introdução}

Das violências que permeiam a vida em sociedade, uma das mais preocupantes é a violência contra a mulher. Este tipo de violência se caracteriza por ser praticada em razão do gênero da vítima e embora possa ocorrer nos mais diversos espaços da sociedade, é muitas vezes difícil de combater, vez que ocorre com frequência dentro do espaço doméstico, sem testemunhas e envolve aspectos delicados, como a afetividade ou a dependência emocional existente entre a vítima e o agressor.

A cultura da violência doméstica advém das desigualdades no exercício do poder, levando a uma relação de "dominante e dominado", que embora tenham acontecido avanços na equiparação entre homens e mulheres, a ideologia patriarcal ainda vigora e a desigualdade sociocultural segue sendo uma das principais razões da discriminação feminina (DIAS, 2007, p. 15-6). 
Considerando os números alarmantes de casos de violência contra a mulher e de violência doméstica no Brasil, números estes que neste momento de pandemia se acentuam ${ }^{2}$, questiona-se: quem violenta as mulheres?

Dedicamos um grandioso tempo na academia para analisar como se desdobra a violência contra a mulher e muito pouco nos perguntamos sobre quem as violenta. Por que os homens sentem-se no direito de agredir? O que faz com que agridam? Por que a violência doméstica tem destinatário e o gênero é feminino?

Para responder a estas perguntas, realizou-se levantamento bibliográfico com o fito de destrinchar conceitos como gênero, masculinidades, violência doméstica. O primeiro referencial teórico pesquisado é a historiadora Joan Scott (1995), que define gênero como um "elemento constitutivo de relações sociais fundadas sobre as diferenças percebidas entre os sexos, sendo assim uma construção social e histórica dos sexos". Sobre o entendimento de masculinidade hegemônica, Connell (2013) afirma que essa "foi entendida como um padrão de práticas [...] que possibilitou que a dominação dos homens sobre as mulheres continuasse".

No que se refere ao conceito de violência de gênero, os principais estudos visitados foram os da socióloga Heleith Saffioti, qual sustenta que o sistema patriarcal-racista-capitalista socializa o homem para dominar a mulher, a qual se submete ao "poder do macho".

Seguindo o método de revisão de bibliografia, foi problematizado como a socialização de cada gênero influencia na manutenção das relações de poder entre os gêneros e na perpetuação da violência de um sobre o outro. Pesquisas nos campos da sociologia das relações de gênero, bem como na antropologia e sociologia do Direito

2 Disponível em: https://www.justificando.com/2020/07/02/por-que-a-violenciacontra-a-mulher-cresce-durante-a-pandemia-da-covid-19/ 
estão sendo fundamentais para a realização deste estudo, ainda em andamento. $\mathrm{O}$ principal resultado da pesquisa, até o momento, foi compreender que a construção social da masculinidade dentro de um sistema patriarcal acaba por formar homens que violentam mulheres, seja de forma física, sexual ou psicológica. Nos estudos de Erica Canuto (2018) foi encontrada a aplicação dos grupos reflexivos de homens como forma de solucionar o problema, uma vez que esses possibilitam a transformação dos padrões socioculturais.

\section{A masculinidade construída}

Para pensar masculinidade, é utilizado neste trabalho o conceito formulado por Joan Scott (1995) que entende gênero como um elemento constitutivo de relações sociais fundadas sobre as diferenças percebidas entre os sexos, sendo assim uma construção social e histórica dos sexos.

O conceito de gênero redebatido por Scott (1995) diz respeito a um sistema de relações de poder fundamentado em um conjunto de características, de identidades e de comportamentos que se opõem e que são atribuídos a sujeitos do sexo feminino e masculino. Assim, entendese que enquanto o sexo é determinado pela natureza, ou seja, pela biologia, o gênero é construído historicamente e depende dos processos de socialização vivenciados pelos indivíduos, processos esses determinados pelo contexto social, político e econômico.

Desta maneira, a referida autora compreende o sexo biológico somente como um demarcador da lógica dicotômica (no sentido de que concebe gênero a partir das diferenciação dos sexos) e relacional (tendo em vista o seu entendimento de que a existência de um está condicionada a do outro), para fazer uma diferenciação dos marcadores sociais de gênero - ou seja, das ideias do que é masculino ou do que é feminino - são atribuídos significados aos corpos e aos objetos dispostos na sociedade. 
Essas definições estão profundamente associadas às representações de poder em uma determinada conjuntura políticosocial e a limitação metafórica atribuída aos conceitos está vinculada às doutrinas políticas, religiosas, jurídicas ou educativas que atribuem e perpetuam as definições fixas do que é ser homem ou mulher, masculino ou feminino (SCOTT, 1995, p. 86).

Scott também traz a compreensão de que gênero é o meio através do qual o poder é articulado na sociedade, uma vez que as características que definem o que é ser homem ou mulher definem permissões, negações ou diferenciações de acesso aos recursos materiais, sociais e políticos disponíveis na sociedade. (SCOTT, 1995, p. 88)

A sociedade delimita, com bastante precisão, os campos em que pode operar a mulher, da mesma maneira em que escolhe os terrenos onde pode atuar o homem (SAFFIOTI, 1987, p. 8). Um dos exemplos disto é a socialização dos filhos, tarefa que, pela tradição, é atribuída às mulheres, mesmo quando esta realiza alguma atividade de trabalho fora do lar. A sociedade despende muito investimento na naturalização deste processo, tentando fazer crer que a atribuição do espaço doméstico à mulher decorre de sua capacidade de ser mãe (SAFFIOTI, 1987, p. 9).

Saffioti, ao discutir o conceito de gênero, também conclui que os seres humanos nascem machos ou fêmeas (SAFFIOTI, 1987, p. 10) e que é através da educação que recebem que tornam-se homens e mulheres. Ou seja, a identidade social é socialmente construída.

Saffioti debate, ainda, que o conceito de gênero não se resume a uma categoria de análise, mas como uma categoria histórica, cuja investigação tem demandado muito investimento intelectual. Ela enfatiza que cada feminista se debruça em um determinado aspecto do gênero, mas que há um campo de consenso: o gênero é a construção social do masculino e do feminino (SAFFIOTI, 2015, p. 47). 
Assim, alerta que não basta conhecer a capacidade humana de transformar o reino natural, é preciso estar atento para o processo inverso que consiste em naturalizar processos socioculturais. Quando se diz que é natural que a mulher ocupe o espaço doméstico, deixando livre para o homem o espaço público, está-se naturalizando um resultado da história (SAFFIOTI, 1987, p. 11).

No início do movimento feminista, a questão da igualdade era primordial, sobrepondo-se às questões sobre a diferença. Somente depois da metade da década de 70 e no decorrer dos anos 80 que as feministas dirigiram sua luta pela igualdade na diferença (ARAÚJO, 2005, p. 46)

No entanto, ainda assim o discurso feminista que enaltecia o feminino corroborou com o dualismo do feminino/masculino, mais uma vez concedendo valores e características diferentes a cada sexo, de maneira que quando se universalizavam essas divergências, ficava deveras difícil enxergar possibilidades para homens e mulheres saírem dos modelos rígidos e estereotipados. Diversas características conferidas ao masculino e ao feminino não são apenas atribuídas pelo gênero, mas também pela classe social, pela cultura, pela educação e por características pessoais e individuais de personalidade, vez que nem "nem todos os homens são agressivos, objetivos, seguros de si etc" e as mulheres não são todas "inseguras, pouco agressivas e sem objetividade" (ARAÚJO, 2005, p. 47-8).

Somente através da libertação dos estereótipos e na construção de novas formas de se relacionar, agir e se comportar que os homens podem se libertar das amarras do machismo, bem como as mulheres podem se libertar dos "imperativos categóricos determinados pelo gênero". A reconstrução do feminino imperiosamente guia à reconstrução do masculino e isso se dá através do conflito, de espaços de luta e tensão dialética, onde estão sempre em jogo poderes e desejos diversos (ARAÚJO, 2005, p. 48) 
As mudanças trazidas pelo feminismo vêm transformando o padrão da masculinidade tradicional, fazendo com que seja indispensável transformá-lo. Repensar o masculino diz respeito a revisitar modelos de conduta, de teorias e de discursos que ao longo da história vem sendo utilizados para explicar a masculinidade (ARAÚJO, 2005, p. 48)

É necessário, dessa forma, repensar a masculinidade, levando em conta as maneiras de dominação e de controle do masculino da mesma forma que os estudos feministas se voltam para a compreensão das formas de controle e violência contra as das mulheres. Os homens possuem, de fato, maior possibilidade de ação e mais liberdade de escolha que as mulheres, no entanto esta liberdade é exercida debaixo de inflexíveis parâmetros. Um homem que apresente um comportamento efeminado é uma vítima em potencial do código de condutas que regula a masculinidade aceita e reconhecida, aquela que é dita como hegemônica (TORRÃO, 2015, p. 142).

Em um projeto da ONU Mulheres, foi liberada uma cartilha ${ }^{3}$ nas redes sociais acerca de uma "Caixa dos homens", ou seja, o conjunto de características que são atribuídas aos homens para que possam ser considerados, de fato, homens. São elas: Heterossexual, fisicamente apto, corajoso, forte, no controle, ativo, sexualmente experiente, tem prontidão sexual, fala firme, não demonstra emoções, sabe se defender, não chora, é sexualmente impositivo, trabalhador, provedor, não comete erros, não desiste, aguenta "o tranco", é competitivo, bemsucedido, dominante em relação à mulher.

Essa ideia encaixa-se nos estudos de Robert Connell (2013, p. 245) sobre masculinidade hegemônica. Em suas palavras, "a masculinidade hegemônica foi entendida como um padrão de práticas 3 Cartilha
https://www.jornalnh.com.br/2018/04/blogs/cotidiano/questao_de_genero/225990
0-a-caixa-dos-homens.html. 
(i.e., coisas feitas, não apenas uma série de expectativas de papéis ou uma identidade) que possibilitou que a dominação dos homens sobre as mulheres continuasse".

A pesquisadora Berenice Bento $(2015$, p. 89) desenvolve que a masculinidade hegemônica constrói uma imagem dessa masculinidade que é aquela dos homens que detêm o poder e que se tornou um modelo em avaliações psicológicas e em pesquisas sociológicas e até mesmo em literatura de autoajuda que incentiva os jovens a tornarem-se "homens de verdade". Como mencionado, a definição de masculinidade é sempre reforçada como sinônimo de força, de sucesso, de capacidade, de confiança, domínio e controle.

Os homens aprendem, em geral, o que eles não devem ser antes mesmo de aprenderem o que eles podem ser, fazendo com que suas identidades sejam construídas de forma negativa. A constante necessidade de aprovação e de reconhecimento do homem como um membro do gênero masculino ocorre a partir da relação com outros homens e da aprovação social masculina (BENTO, 2015, p. 96).

Sócrates Nolasco (2013) define que a busca pelo pertencimento, por querer ser um "homem de verdade", traz à tona diversos esforços cotidianos de afirmação, especialmente em razão de o comportamento masculino permanecer em constante avaliação em nossa sociedade. A masculinidade, assim, é um teste permanente e implacável, de forma que o homem não pode parar de tentar provar o seu próprio valor (BENTO, 2015, p. 95). Há um grande temor de se posicionarem em situações de humilhação ou de desmoralização públicas. Assim, muitos homens privam-se de demonstrar emoções, de demonstrar afeto, carinho, de dispender cuidados com os filhos, bem como de fazer inclusive tarefas domésticas, sob a ideia de que isso é "coisa de mulher", reforçando assim o machismo e a violência inerentes ao patriarcado.

Desta forma, conforme já mencionado, a construção a respeito de gênero é feita através da vivência em sociedade, através dos papéis 
que um ser humano performa nesta sociedade, em razão da cultura. Acaba por ser essa também uma forma de opressão, tendo em vista que define qual lugar uma pessoa pode e ou deve ocupar a partir de posições de poder, limitando a expressão da individualidade de cada um.

Percebe-se, pois, o caráter engessado da construção dos gêneros e, para além disso, o perigoso papel da construção desse tipo de masculinidade: a de formar homens que violentam as mulheres. Todo o discurso em torno do que é ser macho na sociedade reforça o estereotipo da inferioridade da mulher: um homem é entendido socialmente como menos macho do que outro quando apresenta qualquer tipo de comportamento atribuído à mulher. Conforme aduz Berenice Bento (2015, p. 95): “ser homem significa 'não ser como as mulheres'. Esta noção de antifeminilidade reside no centro das concepções de masculinidades, de modo que a masculinidade é definida pela negativa: ser homem é não ser mulher"

\section{Homens, violência doméstica e os grupos reflexivos}

A convenção de Belém do Pará define violência contra a mulher como "qualquer ato ou conduta baseada no gênero, que cause morte, dano ou sofrimento físico, sexual ou psicológico à mulher, tanto na esfera pública como na esfera privada" (Capítulo I, artigo $1^{\mathrm{a}}$ ).

Já na Lei Maria da Penha, a violência doméstica é definida em cinco formas de agressão: a física, a moral, a psicológica, a patrimonial e a sexual. A violência física consiste na concretização das chamadas vias de fato, expressas nas ações de bater, morder, chutar, machucar. Já a violência sexual consiste nas ações capazes de coagir, por qualquer meio, a mulher a prática sexual ou tendente a utilizar de qualquer modo a sua sexualidade. No âmbito moral, a violência se expressa nas ações verbais com o intuito de diminuir a reputação moral da mulher com xingamentos e adjetivações negativas. A violência psicológica consiste 
nas diversas formas comportamentais que causem dano ao emocional da mulher, como ameaças, por exemplo. Por fim, a violência patrimonial consiste nos atos de reter, destruir, subtrair, parcial ou totalmente bens e objetos da mulher (VERAS, 2018, p. 126).

Saffioti $(2015$, p. 18) trata a violência como a ruptura de qualquer forma de integridade da vítima: seja física, moral, psíquica ou sexual. A violência doméstica ostenta características específicas, em que uma de suas mais relevantes é a rotinização, o que colabora bastante para a codependência e o estabelecimento da relação fixada. A relação violenta se trata de uma verdadeira prisão, em que o próprio gênero se encarrega das amarras: o homem deve agredir porque o macho deve dominar a qualquer custo e mulher deve suportar agressões de todo tipo porque o seu "destino" determina (SAFFIOTI, 2015, p. 90).

A Lei Maria da Penha inaugurou um marco de ruptura em relação ao sistema anterior, vez que partimos da proteção insuficiente da Lei 9.099/1995 para a proteção integral da Lei 11.340/2006. A doutrina da proteção insuficiente deixava de lado os interesses da mulher em situação de violência, bem como a questão de gênero que subjaz ao processo e somava um grande número de processos arquivados por prescrição, além de priorizar acordos mesmo contra a vontade da mulher agredida (VERAS, 2018, p. 145).

Os estudos e discussões a respeito da pauta de gênero e das masculinidades permitem perceber que o processo de socialização primária internaliza perspectivas de padrões de comportamentos associados ao masculino e ao feminino, existindo uma evidente associação entre virilidade e masculinidade. Essa virilidade é confundida com força, poder, agressividade e violência. (VERAS, 2018, p. 190)

Erica Canuto (2018, p. 192) também cita Joan Scott para ressaltar que a compreensão da relação entre gêneros e representações sociais de poder apresenta um outro desdobramento, que consiste no 
entendimento de que o gênero é o meio pelo qual o poder é articulado na sociedade, dado que os atributos que definem o que é ser homem ou mulher estabelecem permissões, negações ou diferenciações de acesso aos recursos disponíveis na sociedade, sejam eles materiais, sociais ou políticos.

Considerando que a violência não está associada às masculinidades como essência, mas que é decorrente de uma construção cultural, pode-se pensar em um modelo de responsabilização que atue verdadeiramente nessa perspectiva pedagógica de desconstrução. Responder com punitivismo um problema social não traz resultados efetivos (VERAS, 2018, p. 192).

A solução que o sistema de justiça que aplica a Lei Maria da Penha dá às mulheres não as permite participar, não as escuta e não dá oportunidades de mudanças de conduta ou resolução integral das necessidades dessas mulheres, o que gera uma insatisfação em massa das mulheres que utilizam o Poder Judiciário (VERAS, 2018, p. 193).

Segundo informações do Conselho Nacional de Justiça, no ano de 2016, chegaram 290.423 novas ações penais por crimes de violência doméstica nos tribunais do país, sendo que já existiam 490.327 pendentes, aguardando julgamento, mesmo considerando que 208.901 processos foram arquivados sem qualquer solução, seja pelo decurso do tempo de prescrição, promoção de arquivamento ou outra causa de extinção da punibilidade. O resultado é uma taxa de congestionamento na média superior a $60 \%$, tendo em vista que a velocidade que entram os processos não é a mesma que eles são apreciados pelo judiciário (VERAS, 2018, p. 193).

Em 2016, embora o judiciário tivesse 490.327 processos pendentes, somente 29.192 processos foram para execução penal, o que significa que o percentual de condenação foi de 5,95\%. Enquanto isso, o percentual de arquivamento foi de $42,6 \%$. Aparentemente, o uso do processo penal tradicional, a justiça retributiva, objetivamente, não está 
surtindo o efeito desejado. Poder-se-ia até observar que o uso da Lei 9099/95 também causava um grande número de prescrição e as penas não eram aplicadas. Depois da Lei Maria da Penha, o processo não oportuniza a discussão sobre gênero, violência e reflexão com possibilidade de mudança de comportamento (VERAS, 2018, p. 193).

A Lei Maria da Penha, enquanto microssistema de proteção integral das mulheres em situação de violência doméstica e familiar, previu as medidas protetivas de urgência como o coração desse marco normativo. E fez bem ao garantir o cumprimento dessa ordem de proteção com prisão ao autor desobediente. Se o juiz de direito ordena a proteção da mulher, com previsão de ações e omissões específicas por parte do autor da violência, esta ordem deve ser obedecida para que se garanta que a vítima não será mais vítima. Uma tem demonstrado uma diminuição significativa nos índices de reincidência, em comparação com o modelo retributivo, por oportunizar a discussão de gênero, reflexividade e operar na mudança efetiva de conduta (VERAS, 2018, p. 194).

No Brasil, os grupos reflexivos constituem uma forma de intervenção interessada na problematização de modelos de masculinidade e feminilidade e na construção de alternativas para homens que instrumentalizam a violência em suas relações. Esses grupos são anteriores à Lei Maria da Penha, mas frequentemente se vinculam a ela após sua promulgação em 2006, tendo previsão expressa no seu texto (VERAS, 2018, p. 195).

Segundo Sócrates Nolasco, durante essa trajetória reflexiva os homens estão passando a ter consciência das tensões e dos conflitos que são impostos pelo machismo de descobrindo possibilidades de sair dos estereótipos castradores, reconhecendo suas necessidades afetivas, bem como buscando meios de satisfazê-las sem se sentirem menos "machos" por isso. Somente através dessas novas possibilidades podem descobrir o prazer de amar e de se relacionar de forma diferente, em que haja 
abertura para a intimidade, para a troca afetiva e para o contato com sentimentos (ARAÚJO, 2005, p. 41-52)

Reafirma-se, portanto, a importância de serem realizados trabalhos pedagógicos, com a discussão sobre papéis sociais de gênero, relações de poder, alternativas ao comportamento e comunicação violentos, questionamentos sobre padrões de conduta que legitimam a violência, levando à desconstrução e desnaturalização do comportamento agressivo associado à masculinidade e, por consequência, à virilidade. Acredita-se que a pertinência do manejo dos institutos despenalizadores, como a suspensão condicional do processo, aliados às condições que incluam a vítima no processo de construção da solução para o conflito, atendendo às suas expectativas de proteção integral, reparação dos danos e garantindo a participação efetiva dos homens em situação de violência nos grupos reflexivos pode ser o caminho para prevenir novas condutas agressivas, provocando uma reflexividade apta a produzir uma real mudança de pensamento e conduta no que se refere à violência de gênero contra a mulher (VERAS, 2018, p. 195).

É nessa ideia que se dá a importância das mulheres e dos homens se distanciarem dos padrões de gênero estabelecidos e começarem a desenvolver novas formas de subjetividade.

As relações violentas devem ser trabalhadas no sentido de se tornarem igualitárias, democráticas, na presença portanto, ainda que contidas, autorreprimidas das antigas. As pessoas envolvidas na relação violenta devem ter o desejo de mudar. É por esta razão que não se acredita numa mudança radical de uma relação violenta, quando se trabalha exclusivamente com a vítima. (...) Todos percebem que a vítima precisa de ajuda, mas poucos veem esta necessidade no agressor (SAFFIOTI, 2015, p. 71).

Enquanto a religião exige que os seres humanos se amem uns aos outros, o que depende da convivência, uma vez que nem mesmo o 
amor materno é instintivo, a compreensão dos direitos humanos impõe que cada um respeite os demais. Amar o outro não constitui uma obrigação, mesmo porque o amor não nasce da imposição. Respeitar o outro, sim, constitui um dever do cidadão, seja este outro mulher, negro, pobre (SAFFIOTI, 2015, p. 83).

\section{Considerações finais}

Da análise de gênero a partir das ideias de Joan Scott, restou claro que as concepções de homem e mulher são fruto da socialização dos indivíduos e não consequências advindas naturalmente de seus sexos biológicos. Foi visto que a pesquisadora estabelece que o gênero é o primeiro demarcador das relações de poder dentro da sociedade e que as estruturas de poder vigorantes naquela sociedade se apropriam dessas definições a fim de criar limitações metafóricas para dar um novo significado a esta ideia.

Desses ensinamentos, pode-se concluir que uma vez que gênero é uma construção social, existe uma possibilidade de ressignificar o que é masculino e feminino, e que uma vez que as estruturas de poder na sociedade têm uma inclinação de gênero (pois constroem cenários de concorrência entre homens e mulheres), a mudança de local desses indivíduos nas estruturas de poder da sociedade pode ajudar na transformação desses significados e símbolos que são atribuídos aos gêneros.

Em seguida, buscou-se realizar uma reflexão sobre como a socialização dos homens acaba por torná-los, com frequência, agressores de mulheres, seja física, sexual, psicológica ou emocionalmente. Também concluiu-se que a aplicação dos grupos reflexivos de homens é uma possível solução para descontruir o machismo e permitir aos homens, especialmente aqueles envolvidos em processos de violência doméstica enquanto agressores, refletir sobre 
questões como masculinidade, gênero, violência etc. A vivência dos grupos reflexivos tem dado resultados muito positivos, tornando a reincidência menos provável, uma vez que o contato e o debate acerca das mencionadas questões possibilitam a transformação dos padrões socioculturais.

\section{Referências}

ARAÚJO, Maria de Fátima. Diferença e Igualdade Nas Relações De Gênero: Revisitando O Debate. Psic. Clin., Rio De Janeiro, v. 17, n. 2, p. 41- 52, 2005.

BENTO, Berenice. Homem não tece a dor: queixas e perplexidades masculinas. 2. ed. Natal/RN: EDUFRN, 2015.

CONNELL, Robert W.; MESSERSCHMIDT, James W. Masculinidade hegemônica: repensando o conceito. Revista Estudos Feministas, Florianópolis, v. 21, n. 1, p. 241-282, maio 2013. ISSN 1806-9584. Disponível em: <https:/ / periodicos.ufsc.br/index.php/ref/article/view/S0104026X2013000100014/24650>. Acesso em: 28 de agosto de 2020.

DIAS, Maria Berenice. A Lei Maria da Penha na Justiça: LEI 11.340/2006:da efetividade da lei de Combate à Violência Doméstica Familiar Contra a Mulher. São Paulo: Revista dos Tribunais,2007.

NOLASCO, Sócrates. A desconstrução do masculino: uma crítica à análise de gênero. Rio de Janeiro, Rocco, 1995

NOLASCO, Sócrates. Marc Lépine: violência e masculinidade no contemporâneo. Interfaces Brasil, Belo Horizonte, v. 1, n. 3, p. 29-43, 2003.

SAFFIOTI, Heleieth. Gênero patriarcado violência. 2. ed. São Paulo: Expressão popular: Fundação Perseu Abramo, 2015.

SAFFIOTI, Heleieth. O poder do macho. São Paulo: Moderna. Coleção Polêmica, 2001. 
SCOTT, Joan. Gênero: uma categoria útil de análise histórica. Mulher e realidade: mulher e educação. Porto Alegre: Vozes, v.16, n.2, jul/dez 1995.

TORRÃO FILHO, Amílcar. Uma questão de gênero: onde o masculino e o feminino se cruzam. Cadernos Pagu, n. 24, p. 127-152, jan./jun. $2005 . \quad$ Disponível em: <http://www.scielo.br/pdf/cpa/n24/n24a07>. Acesso em: 26 de agosto de 2020.

VERAS, Erica Verícia Canuto de Oliveira. A Masculinidade no Banco dos Réus: um estudo sobre gênero, sistema de justiça penal e aplicação da lei maria da penha. Natal: Ed do Autor, 2018, p. 356. 